\title{
Can burglary prevention be low-carbon and effective? Investigating the environmental performance of burglary prevention measures
}

\author{
Helen Skudder ${ }^{1,2} \cdot$ Ian Brunton-Smith ${ }^{3}$. \\ Andromachi Tseloni ${ }^{4}$ - Alan McInnes ${ }^{5}$. \\ John Cole ${ }^{2} \cdot$ Rebecca Thompson $^{4}$ - Angela Druckman ${ }^{1}$
}

(C) The Author(s) 2017. This article is an open access publication

\begin{abstract}
There has been limited study to date on the environmental impacts of crime prevention measures. We address this shortfall by estimating the carbon footprint associated with the most widely used burglary prevention measures: door locks, window locks, burglar alarms, lighting and CCTV cameras. We compare these footprints with a measure of their effectiveness, the security protection factor, allowing us to identify those measures that are both low-carbon and effective in preventing burglary. Window locks are found to be the most effective and lowcarbon measure available individually. Combinations of window locks, door locks, external and indoor lightings are also shown to be effective and low-carbon. Burglar alarms and CCTV do not perform as strongly, with low security against burglary and higher carbon footprints. This information can be used to help inform more sustainable choices of burglary prevention within households as well as for crime prevention product design.
\end{abstract}

Keywords Burglary prevention · Crime prevention - Carbon footprint - Carbon cost of crime Security protection factor

Helen Skudder

h.skudder@surrey.ac.uk

1 Centre for Environment and Sustainability, University of Surrey, Guildford GU2 7XH, UK

2 Home Office, HM Government, 2 Marsham Street, London SW1P 4DF, UK

3 Department of Sociology, University of Warwick, Coventry CV4 7AL, UK

4 School of Social Sciences, Nottingham Trent University, 50 Shakespeare Street, Nottingham NG1 4FQ, UK

5 Secured by Design, Crime Prevention Initiatives Limited, 1st Floor, 10 Victoria Street, London SW1H 0NN, UK 


\section{Introduction}

Public concern for the environment is a topical issue; global climate change, in particular, has been identified as one of the greatest challenges of our time (United Nations 2016). Emissions of greenhouse gases, predominantly carbon dioxide $\left(\mathrm{CO}_{2}\right)$, resulting from human activities, are becoming an increasing problem and have recently reached the 'highest levels in history', producing widespread impacts on human and natural systems (Pachauri et al. 2014). Climate change is therefore a global and pressing issue, and the Paris Agreement (UNFCC 2015), which is signed by nearly 200 countries, calls for global greenhouse gas emissions to be reduced. There is a clear need therefore for governments, businesses and individuals to consider their environmental impacts wherever possible. In the UK, the commitment to reduce emissions is enshrined in law through the Climate Change Act (Climate Change Act 2008), and it is important that this permeates all policy areas, including crime prevention (Pease 2009).

The benefits of crime prevention are obvious in terms of reduced burden on society and the economy. Preventing crime saves lives, improves wellbeing, and limits costs associated with property being lost, damaged or wasted (HMIC 2014). Savings are also made in terms of time, work and money expended on dealing with the consequences of crime. The launch of the Modern Crime Prevention Strategy by the Home Office (UK Government department), for example, clearly demonstrates that prevention is a key priority of Government policy (Home Office 2016).

Savings offered by crime prevention, however, may be more than just financial. A study into the carbon cost of crime conducted by Pease (2009) demonstrated that crime could have a substantial impact on the environment in terms of a large carbon footprint and introduced the idea that 'it would be difficult to envisage a high crime society being a low carbon society' (Page 3). A follow-up study by Skudder et al. (2016) went further to produce a detailed assessment of the carbon emitted from criminal activity each year in England and Wales, which was estimated at around four million tonnes $\mathrm{CO}_{2} \mathrm{e}$ (carbon dioxide equivalents) (Skudder et al. 2016). This begs the question whether crime prevention measures produce less carbon than the crimes they prevent. If they do then they potentially provide additional benefits that have previously been overlooked.

In this study, we assess the carbon emissions associated with crime prevention measures. This is believed to be the first attempt to help inform crime prevention specialists of the environmental impact of burglary prevention products and enable comparisons with the carbon emissions of the crimes they aim to prevent. We focus in particular on those measures associated with preventing domestic burglary, as this has been shown to be the offence with the largest overall contribution to the total carbon footprint of crime, accounting for over 30\% of emissions (Skudder et al. 2016). Households in England and Wales rely on a number of security devices to protect them from burglary. The most popular being locks on doors and windows, security lighting, burglar alarms and security chains (ONS 2013). Other forms of security such as CCTV systems are rare in private households (Tseloni et al. 2014, Table 2) but may be increasing in popularity. However, not all devices and their 
combinations can prevent domestic burglary to the same extent (Tseloni et al. 2014). In this study, we identify those security measures, both individually and used in combination, that are the least (and most) carbon intensive. We then compare the carbon costs of each measure with a measure of their effectiveness, known as the security protection factor (SPF) (Tseloni et al. 2014). This allows us to identify winwin measures in terms of security and environmental performance, i.e. measures that are effective at reducing the number of offences that occur, and that also have low emissions associated with this preventative measure.

\section{Crime prevention}

Households with no security measures in place are five times more likely to be burgled than those with modest security measures (police.uk 2016). In particular, the growth of security measures in households and the increasing emphasis on private security have been linked to the drop in property offences (Aebi and Linde 2010; Clarke and Newman 2006; Van Dijk 2007; Vollaard and Van Ours 2011). The increased amount of security devices installed in homes and businesses has also recently been found to be the most likely explanation responsible for the drop in crime since the mid 1990s (Farrell et al. 2014) .

Crime prevention advice from the UK's crime mapping website, police.uk, aims to help households prevent burglary where possible. There are varying types of security for households to implement in order to prevent burglaries from occurring. Alongside routine actions such as keeping doors and windows locked in unoccupied houses, hiding keys out of sight, securing bikes and ensuring gates and fencing are in good condition, the use of good window locks, strong deadlocks and installing a visual burglar alarm along with good outside lighting are encouraged (police.uk 2016). Welsh and Farrington (1999) found that a combination of interventions is needed to impact certain categories of crime. This is because, for example, alarms on their own are ineffective as a prevention measure and a combination of interventions is needed to be successful (Tilley et al. 2015).

Tseloni et al. (2014) explored the presence of security devices and burglary risks in order to establish the effectiveness of each device type, both individually and when used in combination with others. To this end, the study employed populationbased data from the Crime Survey for England and Wales (CSEW) from 2008/2009 to $2011 / 2012$ detailing the use of security devices within homes, to produce a SPF for each device type. The SPF was calculated using a Security Impact Assessment Tool (SIAT), initially developed to test the effectiveness of security measures against car theft (Farrell et al. 2011). The SIAT compares the overall burglary risk to the burglary risk of households without security and those with particular security devices (either individual devices or combinations). The SPF values therefore indicate the level of security conferred relative to the absence of security devices. The burglary security measures examined included door and window locks, security chains, burglar alarms, indoor and external lights, window grilles or bars, dummy alarms and CCTV systems. They found that external lights or door locks offered the highest protection against burglary of households relying on a single security 
device. One of the most effective combinations of devices included window and door locks, indoor and external lighting (known as WIDE_-referred to as EIWD in Tseloni et al's. study), which afforded 49 times more protection against burglary than no security (Tseloni et al. 2014). Rather surprisingly, however, alarms in properties without any other device slightly increased burglary risk compared to no security. Furthermore, adding a burglar alarm reduced the overall preventive effectiveness of most security combinations. Tilley et al. (2015) highlighted that burglar alarms, although having high plausibility to prevent burglary, are unlike door or window locks, as they do not create a physical obstacle to burglary. Also alarms do not increase the risk to a potential burglar approaching the target property, as would be the case with external lights or CCTV. Alarms may indeed act as flags for criminals to target properties or they may simply be installed but not used; or, if triggered, they are ignored by neighbours, passers-by and the police, making them ineffective (Tilley et al. 2015).

Increased security adds value in terms of social and economic benefits as people avoid becoming victims (Clarke and Weisburd 1994). An opinion poll concerning desirable factors in the design of homes indicated that 'security against crime' was the most important factor (Mori Social Research Institute 2002). Nationwide crime prevention initiatives, such as Secured by Design (SBD), therefore aim to encourage the building industry to design out crime at the planning stage and encourage businesses and households to implement Crime Prevention Through Environmental Design (CPTED) principles where possible. SBD advice and guidance relating to these principles is proven to reduce the chance of burglary by up to $75 \%$ (Secured by Design 2015). CPTED has evolved over many years and is based on many early studies (Angel 1968; Clarke and Mayhew 1980; Gardiner 1978; Jacobs 2010; Jeffery 1971; Lynch 1960; Newman 1973; Poyner 1983). The five essential elements of CPTED include surveillance, access, territoriality, management and maintenance, and physical security. Although crime prevention initiatives, such as SBD, do not rely solely upon physical security, the standards set to which doors, windows, fences and other household products must adhere suggest that physical security is viewed as a crucial factor (Armitage and Monchuk 2009a). The recent update of the building regulations in England has included a section on household security, known as approved document Q (HM Government 2015), which prescribes standards to which windows and doors must adhere, addressing the 'access' and 'physical security' principles, although these only apply to newly built homes.

The environmental benefits or pitfalls, however, of increased security have yet to be explored in any great detail despite a clear relationship between crime prevention and environmental considerations in the pursuit of sustainability. Cozens (2007) recommended that researching areas of potential conflict between ecological sustainability and designing out crime would aid urban sustainable development efforts. Existing guidance relating to community safety highlights that designing out crime should be central to the planning and delivery of new developments, in order to ensure sustainable communities, where crime and disorder do not undermine quality of life or community cohesion (Home Office 2004). As part of Pease's (2009) study to estimate the carbon cost of crime and its implications, it was concluded that further improvement in designing out crime from environments was 
needed for crime reduction to take its place in the greening of social policy (Page 4). Armitage et al. (2008) assessed the conflicts and synergies between SBD accreditation (ensuring that new homes/developments implement CPTED principles and design out crime where possible) and the UK's Code for Sustainable Homes ${ }^{1}$ (a national standard for the construction and design of new homes). Encouragingly, the study did not identify any features of sustainable design that would prevent a development from achieving the SBD accreditation and equally, no features of SBD security were identified which would make it difficult to achieve a high rating on the Code for Sustainable Homes. Implementing SBD principles therefore does not prevent a developer from achieving high levels of sustainability and vice versa. Armitage and Monchuk (2009b) suggested that poorly designed areas which require premature refurbishment and regeneration, along with additional costs derived from moving home from crime-challenged areas, may have an increased carbon footprint. Pease (2009) adds to this discussion with the assertion that the costs, both fiscal and carbon, of crime reduction through SBD compliance could be recovered over a period as short as four years. Well-known environmental assessment schemes such as BREEAM (although not exclusive to homes) include credits awarded for safe access and the security of the site or building (BRE 2016). This again demonstrates the synergies that already exist between sustainability and security, but the more specific analysis of individual crime prevention measures in terms of environmental impact is still to be developed fully.

In order to justify the use of crime prevention measures, it is important that the benefits outweigh the costs involved. These can either be economic, social or environmental costs/benefits and each are important to consider as part of decision making when assessing security requirements. The Home Office use a national database to estimate the economic and social 'cost of crime', and the most recent estimates present the monetised cost of domestic burglary (in a dwelling) to be around $£ 4000$ (Home Office \& Ministry of Justice 2011). This monetised figure includes the physical and emotional impact on victims (£800), average value of property stolen or damaged ( $£ 1200)$, the cost of police investigations ( $£ 700)$, the cost of other criminal justice system services such as courts, probation and prison services (£700) and the costs associated with anticipation of the offence including defensive expenditure and insurance (£400).

A recent study added to this body of research by estimating an intangible environmental cost of crime, in the form of a carbon footprint. In order to estimate the carbon arising from crime, conversion factors that estimated the carbon emissions associated with spending in different sectors of the economy were applied to the monetised cost of crime estimates (Skudder et al. 2016). The carbon footprint attributed to an incident of domestic burglary was estimated to be just over 1 tonne (1154 kg) $\mathrm{CO}_{2} \mathrm{e}$, equivalent to around 2750 miles of driving an average passenger car. These emissions arose from several sources, including defensive spending $(150 \mathrm{~kg})$, policing $(190 \mathrm{~kg})$, replacing stolen or damaged property $(550 \mathrm{~kg})$ and the

\footnotetext{
1 The Department for Communities and Local Government (DCLG) has recently removed the Code for Sustainable Homes as changes were made to Planning and Building Regulations (HM Government 2015), resulting in some elements that are revised or lost.
} 
criminal justice system, including courts, probation and other services $(120 \mathrm{~kg})$. We use this carbon footprint estimate of burglary from Skudder et al. (2016) as the baseline against which the environmental impact of burglary prevention measures is compared.

\section{Methodology}

In this study, we established the carbon footprint of commonly considered burglary prevention measures and compared these to the footprint of an incidence of burglary. The footprints are estimated using data from environmental declarations scaled up to an average household footprint by multiplying by the number of measures expected in a typical household. ${ }^{2}$ We estimated the footprint of both individual measures and those used in combinations within households. We also compared the environmental performance of the measures with an indicator of their effectiveness, their SPF, estimated by Tseloni et al. (2014), to establish which measure, or combinations of measures, were most preferable if effective and lowcarbon burglary prevention is required.

The measures studied included those in the Crime Prevention Module of the Crime Survey for England and Wales (CSEW): door double locks or deadlocks, window locks, external lights on a timer or sensor, indoor lights on a timer or sensor, CCTV, burglar alarms and security chains. ${ }^{3}$ Where no environmental information was found relating to specific measures, it was not estimated. We highlighted these products in order to recommend that companies address these gaps. Details of the steps carried out to estimate the carbon footprints of crime prevention measures are described below.

\section{Carbon footprinting crime prevention measures}

All products and services have an environmental impact, whether during their production, use or disposal (European Commission 2003). To establish the carbon footprints of burglary prevention products, we used existing studies that consider all carbon emissions associated across all aspects of the product's life cycle. These studies are known as life cycle assessments (LCAs) and estimate emissions associated with the product from raw material extraction all the way to disposal, including the manufacturing of the product and emissions associated with its use (electricity for example). LCAs also take into account any recycling or re-use

\footnotetext{
2 A typical home was assumed to have 3 doors (with 2 locks on the front door and 1 on each rear door), 8 windows (with 1.4 locks per window), 1 burglar alarm system (made up on a control unit, an alarm ringer and 2 sensors, 1 indoor light (to create the illusion of someone occupying the house), 3 external lights (one by each door) and 3 CCTV cameras (one by each door). The calculations and assumptions relating to this typical household are detailed fully in Appendix 2.

3 Similar to Tseloni et al. (2014), we have omitted dummy alarms and window bars or grilles from our analysis as these products are rare (have a low prevalence within the survey) and are largely undesirable in modern households, in comparison to the more widely used measures such as window and door locks, burglar alarms or lighting on a timer or sensor.
} 
applications before final end-of-life disposal. More specifically, in this study, we utilised environmental declarations, which are a standardised type of LCA study, which enable comparisons between products that provide the same function (BSI 2010). Environmental declarations are defined by an international standard (ISO 14025) and are becoming increasingly important as a means of communicating environmental impact data about products in the supply chain. They also, in theory, give contractors and clients more confidence when specifying and procuring products (Ghumra 2016). The declarations summarise details of the environmental impacts of the product under scrutiny, including the global warming potential ( $\mathrm{GWP}$-measured in $\mathrm{kg} \mathrm{CO}_{2} \mathrm{e}$ ), for each aspect of the product's life cycle. Across this life cycle, the total amount of these emissions represent the total embodied carbon (or carbon footprint) of the individual product, which this study used in order to compare products. It should be stressed that the ultimate goal of carbon footprinting is to reduce environmental impacts rather than deliberating on the level of accuracy of the results (RICS 2012).

There are a variety of environmental declaration schemes across industrial sectors, such as EcoLeaf, eco-profile, environmental product declarations (EPD), environmental profiles and product environment profiles (PEP) (BSI 2010). EPDs, for example, cover products related to the construction industry, whereas Ecoleaf and PEPs cover electronic products. An example of the results provided within an EPD is given in Fig. 1.

The use of existing environmental declarations had its advantages: first, it negated the necessity to perform new LCA studies for the specific products of focus (performing LCAs are time-consuming, data intensive, expensive and can include the challenge of commercially sensitive data). Also, as environmental declarations follow a set of strict rules and standards, their results make them suitable for comparison across products, and thus help inform choices between which burglary prevention measures are the most suitable.

\section{Eligibility criteria}

Details of the search strategy used to find environmental declarations can be found in Appendix 1. For declarations to be eligible for inclusion in the study, several criteria had to be met. These are outlined in Table 1.

The smallest, largest and average (median, to discount outliers) footprints found in each set of declarations were used as the indicative footprint for the burglary prevention products. The smallest provides an idea of the minimum footprint expected from the measure, the largest the maximum expected and the median the most likely estimate of the footprint. It should be noted that although there are many different types of each of the crime prevention measure available to buy from a consumer perspective, many are likely to be of similar material composition (most door locks are made from aluminium alloys for example), and also potentially of similar size and shape. ${ }^{4}$ As such, using the footprint of those products with an

\footnotetext{
4 Although it is important to note that varying lock types exist, such as rim locks and multi-point locks, which can differ significantly in construction and material composition.
} 


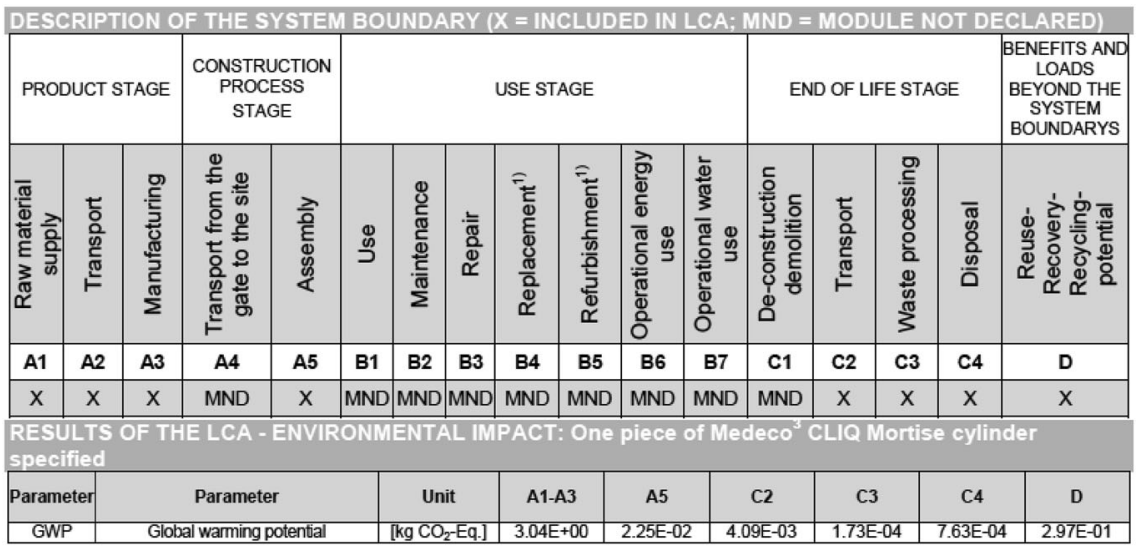

Fig. 1 Section of EPD results table example (Assa Abloy 2015)

environmental declaration to represent those products that do not yet have an environmental declaration is deemed reasonable.

\section{Number of security measures installed per household assumptions}

In order to estimate the carbon footprint of the burglary prevention measures installed in a home, the number of measures per typical household must be estimated. Table 2 details the number of each measure used to estimate the footprint per household (with full methodology calculations detailed in Appendix 2). A lifespan of the presence of these products within the household over 10 years was assumed in order to make the household footprints comparable. The household footprint of each measure was found by multiplying the individual measure footprint by the number assumed present in each household.

\section{Establishing low-carbon and effective measures}

Once a household footprint was established, measures were then assessed on their own within a household and when used in combination. It is common, for example, for houses to have both secure door locks and window locks, and some may choose to install CCTV or burglar alarms, or use external lighting or indoor lights as burglar deterrents. We used Tseloni et al. (2014)'s full SPF database (the extended version of their Table 2) to compare combinations of measures. Security chains as a measure were included within the original Tseloni et al. study, but were omitted from this study since no footprint estimate was available. This resulted in 30 combinations, instead of the original 55 within the Tseloni et al. study. ${ }^{5}$ The footprint of the combinations of measures was calculated by adding the footprint of

\footnotetext{
5 There are a greater number of combinations possible but only those present in more than 50 households within the original survey data from 2008/2009 to 2011/2012 were analysed, and we maintained this threshold in our study for consistency and comparability.
} 
Table 1 Criteria for inclusion within study

\begin{tabular}{ll}
\hline Burglary prevention measure & Inclusion criteria \\
\hline All measures & Environmental declarations must adhere to ISO 14025 standard \\
& and include the GWP impact category so that carbon emission \\
& estimates could be made \\
& Products must have a security application and must be for domestic \\
use, excluding products with exclusively commercial use \\
Products must reflect the broad category of burglary prevention \\
measure detailed within the CSEW. An environmental \\
declaration of an entire door is not representative of the carbon \\
footprint of a door lock and similarly for an entire window and a \\
window lock. As many door and window locks are integrated \\
into the door or window, only those declarations relating to the \\
locking mechanism were selected \\
Only those declarations which related to window fixtures and \\
fitting were used to represent 'window locks' \\
Declarations referring to door locking cylinders or similar \\
hardware were used to represent 'double door lock or \\
deadlocks'
\end{tabular}

Lighting (indoor and external lights on a timer or sensor)

CCTV systems

Burglar alarms
Lighting products selected had to include a sensor or timer to have a security application, thus excluding the many environmental declarations relating to more general lighting either in the home or for industrial applications

Any type of lighting was included, ranging from LED to halogen bulbs, so not all would be considered energy efficient or lowcarbon options (LEDs are more energy efficient than other light bulbs and thus lower carbon)

No declarations were found relating to solar-powered external lights on a sensor, and so an estimate of these is not available as part of this analysis. It would be anticipated that a solarpowered security light would have a much smaller footprint due to the renewable energy providing electricity for the in-use phases (B1-B7 in Fig. 1) of the life cycle assessment but only LED or halogen lights are included here

Whether the lighting was suitable for indoor or outdoor use was sourced from product websites

Only cameras with a sensor or those with surveillance capabilities were included within the study

The search only included declarations relating to the camera rather than an entire CCTV system. This is a limitation. Although many camera declarations found related to network cameras and therefore potentially have associated emissions from computer equipment or use of the internet to view the footage, the wide variability of these systems may overestimate the footprint and so only the camera equipment itself is included within the estimate

Separate environmental declarations were searched for relating to each of the individual parts which make up a burglar alarm system, including the alarm ringer (siren), the control unit and the sensors installed around the home

Environmental declarations for dummy/false alarm boxes were not found and so are not included within this study 
Table 2 Summary of assumptions of number of each security measure within a typical household

\begin{tabular}{|c|c|c|}
\hline $\begin{array}{l}\text { Crime prevention } \\
\text { measure }\end{array}$ & $\begin{array}{l}\text { Assumptions of number } \\
\text { within a household } \\
\text { over a } 10 \text {-year lifespan }\end{array}$ & Details (full calculations available in Appendix 2) \\
\hline Door locks (D) & 4 & $\begin{array}{l}\text { Three doors (two locks on front and one } \\
\text { on each back door) }\end{array}$ \\
\hline Window locks (W) & 11.36 & Eight windows, 1.42 locks on each \\
\hline Burglar alarm (B) & 1 system & $\begin{array}{l}\text { A system comprises of a control unit, an alarm } \\
\text { (ringer) and two sensors }\end{array}$ \\
\hline Indoor lights (I) & 1 & $\begin{array}{l}\text { Only one indoor light on a sensor or timer was } \\
\text { assumed to be needed to create the illusion of } \\
\text { someone occupying a house to deter burglars }\end{array}$ \\
\hline External lights (E) & 3 & Three lights (one by each door) \\
\hline $\operatorname{CCTV}(\mathrm{C})$ & 6 & $\begin{array}{l}\text { Three cameras (one by each door) and each } \\
\text { replaced after five years }\end{array}$ \\
\hline
\end{tabular}

the measures together. We calculated the minimum, median and maximum, for each household measure combination in order to establish what the likely footprint would be, and the best and worst-case scenarios for each measure.

The carbon footprint of a burglary (excluding carbon arising from burglary protection which these prevention measures represent) is estimated at around 1000 $\mathrm{kgCO}_{2} \mathrm{e}$ (Table S6, Skudder et al. 2016). When the household carbon footprints of the measure(s) were compared to the carbon footprint of one incident of burglary, those that resulted in a higher footprint than that of burglary were deemed carbon intensive and designated low environmental performance. If, however, the measure(s) had a lower carbon footprint than the footprint attributed to a burglary, they effectively may offer a net carbon saving (if the products prevent the offence from occurring): these products were categorised as high environmental performance and are preferable over those with low performance. To make the above comparison straightforward and highlight those measure(s) that provide greater carbon savings when compared to a single burglary incident, a carbon payback ratio was calculated by dividing the footprint of a burglary by the footprint of the security measure. A carbon payback ratio equal to one implies that security measure(s) produce the same amount of carbon as the burglary incident they prevent. A burglary prevention measure or a combination of measures with a carbon footprint three times greater than the footprint of a burglary would yield a carbon payback ratio of 0.33 , indicating a greater carbon cost for the prevention measure than for the offence itself. Conversely, a prevention measure (or combination) with a carbon footprint half that associated with burglary would produce a carbon payback ratio of 2 , and those with even smaller footprints yield higher carbon payback ratios. Therefore security measures and their combinations with carbon payback ratios higher than one are deemed to perform well with respect to environmental concerns.

To identify those measures that not only showed high environmental performance, but also were more effective at protecting against burglary, we then plotted 
the measure(s) by both the carbon payback ratio and their effectiveness indicator (SPF). The SPF is also a ratio measure as it indicates the level of security conferred relative to the absence of security devices: Burglary prevention measure(s) with a SPF less than one indicate worse protection than no security at all (lack of effectiveness). Those with SPF higher than one confer greater protection than no security (good preventive effectiveness) (Farrell et al. 2011; Tseloni et al. 2014). This enables us to highlight the most ideal measure(s) using these comparisons to identify those with high environmental performance and high effectiveness.

\section{Results}

\section{Product footprints}

Our search for environmental declarations relating to burglary prevention measures yielded 45 declarations eligible for inclusion within the study. Table 3 summarises these and their associated average carbon footprint estimates. The crime prevention measure with the highest individual carbon footprint is the burglar alarm control unit $\left(352.3 \mathrm{~kg} \mathrm{CO}_{2} \mathrm{e}\right)$, and the lowest is door locks (3.1 $\left.\mathrm{kg} \mathrm{CO}_{2} \mathrm{e}\right)$. For full details of the declarations, see Appendix Table 7.

Figure 2 details the median, minimum, maximum and interquartile ranges ${ }^{6}$ of carbon footprint estimates found within the environmental declarations. Burglar alarm sensors and CCTV show the largest range of any of the measures. In contrast, window and door locks footprint estimates are much more clustered around the median value.

\section{Household footprint and comparison with footprint of burglary}

Table 4 details minimum, median and maximum carbon footprint estimates per household and the resulting best, median and worst-case scenarios of potential carbon payback ratios when compared to the footprint of a burglary. The carbon payback ratios are calculated by dividing the footprint of a burglary by the household footprint of the security measure. For example, the installation of door locks shows the highest payback ratio with around 80 times fewer carbon emissions than allowing a burglary to take place $\left(1000 \mathrm{kgCO}_{2}\right.$ e for a burglary divided by 12.5 $\mathrm{kgCO}_{2} \mathrm{e}$ - the median footprint of door locks within a typical household). Of course, the minimum footprint results in the best-case carbon payback ratio and the maximum footprint in the worst case. None of the measures included within the study have a footprint higher than burglary (all carbon payback ratios were higher than one). Even the measure with the largest individual footprint, burglar alarms, still resulted in between 2 and 3 times fewer emissions than those associated with a single incident of burglary. The following sections focus on the median carbon

\footnotetext{
${ }^{6}$ Burglar alarm control unit and burglar alarm ringer estimates based on only two declarations and so the median and quartiles are estimates between the two (high and low) values.
} 
Table 3 Number of environmental declarations included within study and associated carbon footprints

\begin{tabular}{llc}
\hline $\begin{array}{l}\text { Burglary prevention measure } \\
\text { (from CSEW) }\end{array}$ & $\begin{array}{l}\text { Number of environmental } \\
\text { declarations included within study }\end{array}$ & $\begin{array}{l}\text { Median carbon footprint } \\
\left(\mathrm{kg} \mathrm{CO}_{2} \mathrm{e}\right) \\
(\mathrm{Mean} \text { when }<2)\end{array}$ \\
\hline Door double or deadlocks & 11 & 3.1 \\
Window locks & 3 & 4.2 \\
Burglar alarm & 2 (control unit) & 352.5 \\
& 10 (sensor) & 5.4 \\
Indoor lights (on a sensor or timer $\left.{ }^{\mathrm{a}}\right)$ & 2 (ringer) & 26.5 \\
External lights (on a sensor or timer) & 4 & 60.4 \\
Security chain & None found & 134.5 \\
CCTV & 7 & 66.3 \\
\hline
\end{tabular}

${ }^{a}$ Indoor lighting for security purposes would normally be on a timer to create the illusion of someone being in the household. However, no environmental declarations that specifically mention timers were found; so the indoor lights on a sensor are used as a proxy for this

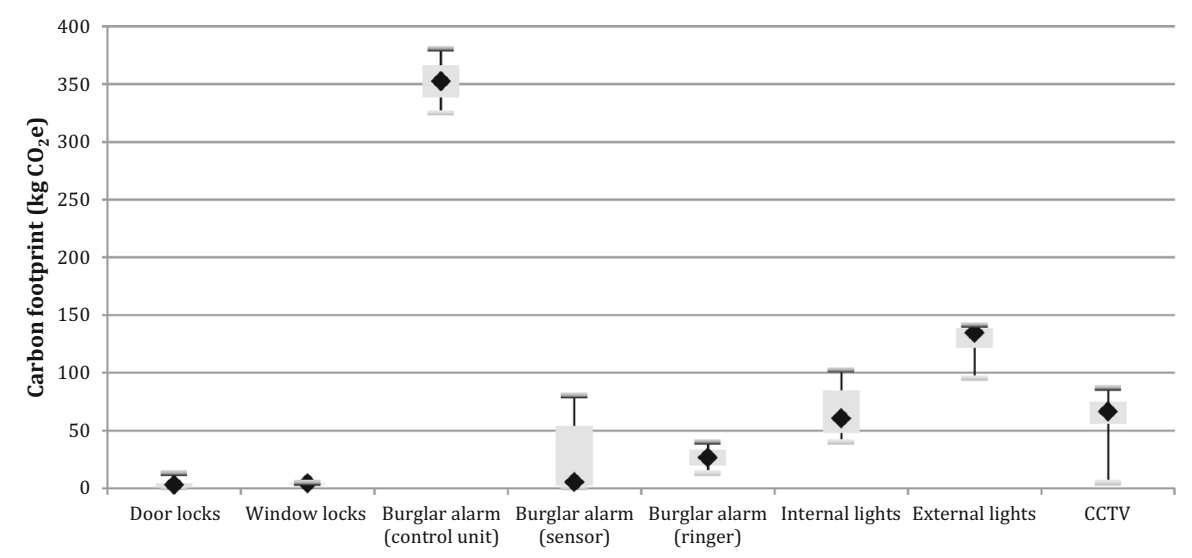

Fig. 2 Highest, lowest, inter-quartile range and average (median) carbon footprints of different burglary prevention measures from environmental declarations

payback ratios and compare individual devices and combinations to a measure of their effectiveness.

\section{Carbon payback and crime prevention effectiveness}

Figure 3 compares the carbon payback ratios of individual crime prevention measures with their SPFs. This enables us to identify the effectiveness and environmental performance of each measure. The most desirable measures (high environmental performance and high effectiveness) are located towards the top or 
Table 4 Burglary prevention measures, carbon footprint (min, max and median) per household and carbon payback ratio

\begin{tabular}{|c|c|c|c|c|c|c|}
\hline \multirow[t]{2}{*}{ Crime prevention measure } & \multicolumn{3}{|c|}{$\begin{array}{l}\text { Carbon footprint per household } \\
\left(\mathrm{Kg} \mathrm{CO}_{2} \mathrm{e}\right)\end{array}$} & \multicolumn{3}{|c|}{$\begin{array}{l}\text { Carbon payback ratio } \\
\text { (burglary footprint over security } \\
\text { footprint) }\end{array}$} \\
\hline & Minimum & Median & Maximum & Best case & Median & Worst case \\
\hline Door locks (D) & 1 & 13 & 51 & 673 & 80 & 20 \\
\hline Window locks (W) & 44 & 48 & 50 & 22 & 21 & 20 \\
\hline Burglar alarm (B) & 339 & 390 & 581 & 3 & 3 & 2 \\
\hline Indoor lights (I) & 40 & 60 & 102 & 25 & 17 & 10 \\
\hline External lights (E) & 286 & 404 & 423 & 3 & 2 & 2 \\
\hline CCTV (C) & $26^{\mathrm{b}}$ & 398 & 519 & 38 & 3 & 2 \\
\hline
\end{tabular}

${ }^{a}$ Calculations may not sum due to rounding to nearest whole number. See Appendix Table 8 for all results combinations to 1 decimal place

${ }^{\mathrm{b}}$ Environmental declaration did not include in-use life cycle stage, which explains the smaller overall footprint

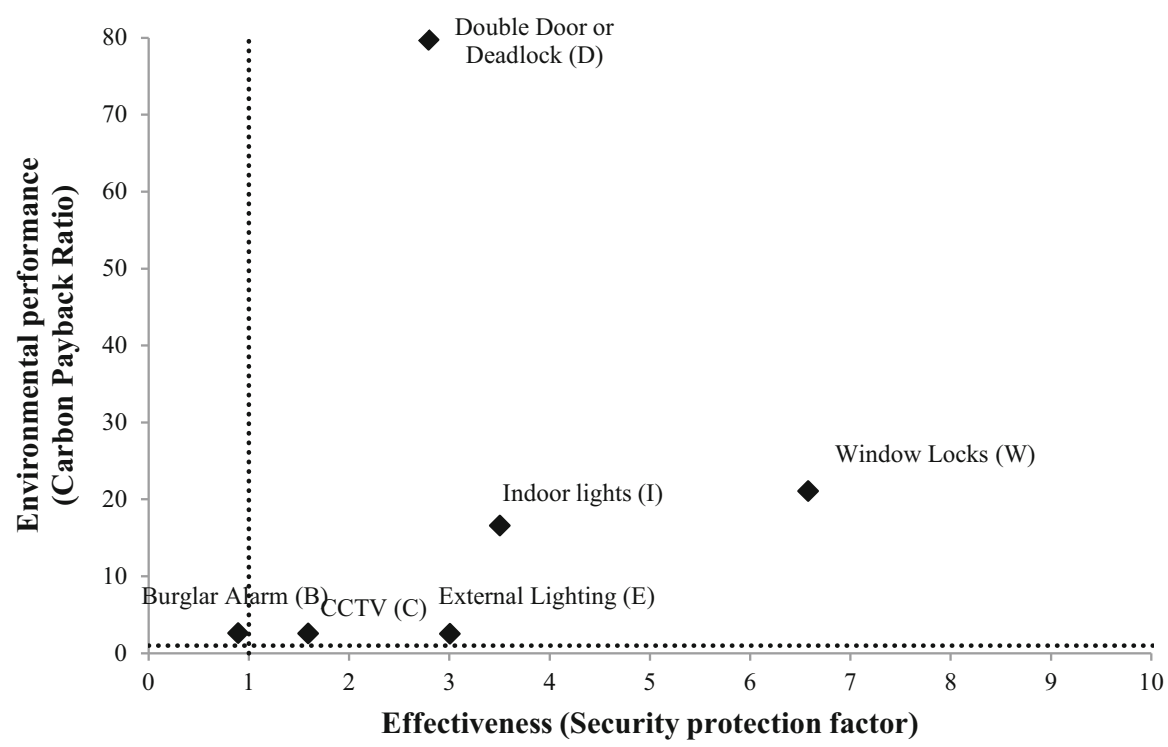

Fig. 3 Burglary prevention measures plotted by their effectiveness and carbon payback ratio (median values only). Notes Measures with a carbon payback ratio lower than 1 (below the horizontal dotted line) are more carbon intensive than one incident of burglary, and measures that have an SPF of lower than 1 (left of the vertical dotted line) offer less protection than no security at all

towards the right of the diagram and those towards the bottom or the left are seen as the least desirable.

Measures with a carbon payback ratio lower than 1 (below the horizontal dotted line) are shown to be more carbon intensive than an incidence of burglary (at 1000 
$\mathrm{kg} \mathrm{CO}_{2} \mathrm{e}$ per incident). There are, however, no measures below this line as all measures have a carbon payback ratio higher than 1 . The measure with the highest carbon payback is shown to be double door or deadlocks with nearly 80 times fewer carbon emissions emitted than that compared with an incidence of burglary.

The measures are spread between left and right on the SPF scale, highlighting those that are more or less effective. Window locks and indoor lights are highest in effectiveness, albeit both with non-statistically significant SPF's (Tseloni et al. 2014), whilst also having a high environmental performance (between 17 and 21 times fewer emissions than burglary). These measures therefore may also be seen as desirable individual measures. If the statistical reliability of burglary prevention (SPF) is to be considered alongside environmental performance, the best individual measure is door double or deadlocks and the second best external lights.

The least desirable individual measure is burglar alarms, as they have a comparatively low environmental performance (only 3 times fewer emissions than burglary) and a SPF lower than 1, meaning that they offer less protection than no security at all (left of the vertical dotted line). This is supported by Tseloni et al. (2014), who suggested that a house with a burglar alarm and no other security may flag the existence of valuables and/or that burglar alarms alone may have been fitted to previously (in the months before the CSEW reference period) burgled homes and thus may indicate undocumented/unobserved repeat victims. Although it should be noted that a property with a burglar alarm and no other security is rare, as only 212 $(0.6 \%)$ out of around 37,000 properties included in their study reported this combination of devices (Tseloni et al. 2014, Table 1).

Figure 4 shows the combinations of measures' carbon payback ratio and SPF, again plotted to show comparisons between the effectiveness and the environmental performance of these measures. The carbon footprints of the measures included in the combination were added together before being divided by the footprint of burglary to derive the carbon payback ratio. For example, the footprint of the WIDE combination is around $524 \mathrm{~kg} \mathrm{CO}_{2} \mathrm{e}(404 \mathrm{~kg}$ for external lighting, $60 \mathrm{~kg}$ for internal lights, $48 \mathrm{~kg}$ for window locks and $13 \mathrm{~kg}$ for door locks), which divided by the $1000 \mathrm{kgCO}_{2} \mathrm{e}$ from an incidence of burglary gives a carbon payback ratio of 2.2. The combination footprints are denoted by capital letters of the first letter of the measures: D for Double or deadlocks, W for window locks, B for burglar alarm, C for CCTV, E for external lighting and I for indoor lighting.

The most desirable combination for burglary prevention (right hand side of the diagram) is external and indoor lights with window and door locks (WIDE) and external lights, window and door locks (EWD). Also considered desirable in terms of carbon are the measures clustered in the top left section, which have higher environmental performance, but a slightly lower effectiveness (although these measures still offer more protection than no security). These include all possible combinations of indoor lights, window and door locks (WD, ID, IW and IWD).

The least desirable combinations (nearest the bottom left of diagram), with low effectiveness and low environmental performance include external and indoor lights with window locks and burglar alarm (EIWB); external lights with burglar alarm and door locks (EBD); external lights with window locks, burglar alarm and door locks (EWBD); and external lights with window locks and burglar alarm (EWB). 


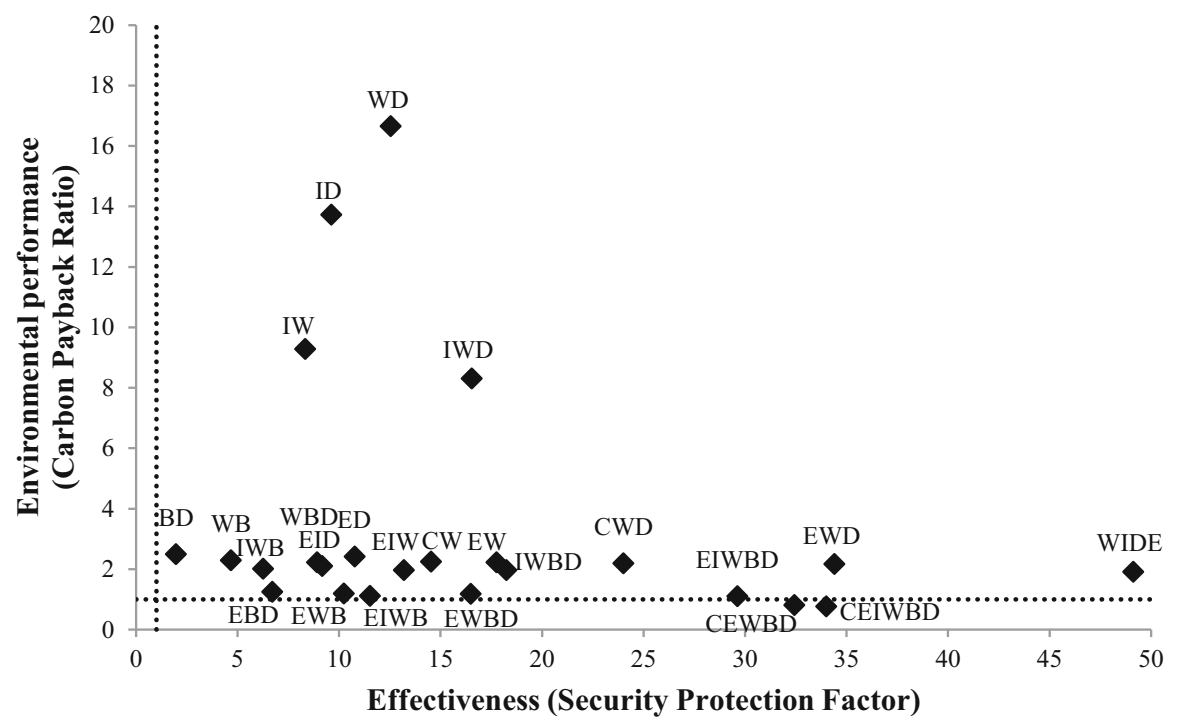

Fig. 4 Combinations of burglary prevention measures plotted by their effectiveness and carbon payback ratio (median only). Notes Measures with a carbon payback ratio lower than 1 (below the horizontal dotted line) are more carbon intensive than one incident of burglary, and measures that have a SPF of lower than 1 (left of the vertical dotted line) offer less protection than no security at all. Abbreviations as per Fig. 3.

Common to all these combinations is the burglar alarm, which reflects its poor individual performance. Also undesirable are the combinations with five or six measures (bottom right of diagram) with higher effectiveness but a lower environmental performance. The CEWBD combination (all measures but indoor lighting) and all six measures combination (CEIWBD), in particular, have a carbon payback ratio lower than one, meaning they are more carbon intensive than an incidence of burglary (at $1000 \mathrm{~kg} \mathrm{CO}_{2} \mathrm{e}$ ), which is considered undesirable.

\section{Discussion}

The social and economic benefits of reducing crime are well understood, but the potential environmental benefits are yet to be developed fully (Pease 2009; Skudder et al. 2016). Actions taken to prevent crime are not exempt from the current global effort to reduce emissions. The aim of this study was to estimate the carbon impact of burglary prevention measures and identify those that are both low-carbon and effective. By analysing environmental declarations of commonly used burglary prevention products, we have estimated the average carbon footprint of various measures, including door and window locks, security lighting, burglar alarms and CCTV systems. This study is believed to be the first review of carbon footprint information related to burglary prevention measures.

We have highlighted that in terms of environmental impact, burglary prevention measures installed in households have relatively small carbon 
footprints (between 12 and $400 \mathrm{~kg} \mathrm{CO}_{2} \mathrm{e}$ ) with no individual measure exceeding the carbon footprint associated with an incidence of burglary $\left(1000 \mathrm{~kg} \mathrm{CO}_{2} \mathrm{e}\right)$. All individual measures considered produce less than half the emissions associated with a burglary, and in some cases, produced over 80 times fewer emissions than a single burglary, showing potential carbon paybacks if burglaries can be avoided by implementing these measures. Only two combinations of measures (one with five measures and one with six) exceeded the footprint of a burglary.

Of course, the desirability of these measures is subject to their effectiveness at preventing burglaries from occurring. We therefore plotted the carbon payback ratio (footprint of burglary over the footprint of the measure) alongside an effectiveness indicator (the security protection factor or SPF). When burglary prevention measures are used in isolation, window locks, indoor lighting and door locks are found to be the most desirable as they are highest on the environmental performance scale (with higher carbon payback ratios) and highest on the effectiveness scale. When combinations of measures were analysed, the most desirable combinations include window locks, door locks, indoor and external lighting (WIDE). The least desirable combinations (lower environmental performance and lower effectiveness) were those that included burglar alarms.

\section{The way forward}

The current study can be expanded in a number of ways. The availability of environmental declarations to estimate the carbon footprints is central to this work. As environmental declarations are very product specific, the results can vary considerably due to the sources of data used, the product designs or manufacturing techniques. ${ }^{7}$ However, only comparing declarations with matching stages would vastly diminish the sample size. Where major differences between declarations in similar product groups were found, this was highlighted (see Fig. 2).

Also, as environmental declarations are costly to undertake and produce, it is likely that only 'higher spec' or 'higher grade' products generally have environmental declarations. Lower grade products may have differing environmental impacts (such as the carbon intensity of the manufacturing process), but these are difficult to estimate and so results may be biased towards representing the impacts of only higher-grade products. ${ }^{8}$ Future work would ideally include a larger number of environmental declarations for each product type and include those of varying quality (and higher and lower prices).

\footnotetext{
7 For example, the burglar alarm sensor declarations detail varying levels of carbon associated with the in-use phase; one as low as $0.5 \mathrm{~kg} \mathrm{CO}_{2} \mathrm{e}$ over the 10-year lifespan, and the highest at around $55 \mathrm{~kg} \mathrm{CO}_{2} \mathrm{e}$. The life cycle stages (A1-D in Fig. 1) included or excluded in the system boundary vary across declarations, which also complicates comparability.

${ }^{8}$ This may be a particular issue with burglar alarms and their installation cost (and one would assume ensuing quality) as they vary widely between below $£ 100$ and over $£ 1000$. A surveyed average installation cost of $£ 475+£ 150$ a year maintenance was estimated for a 3-bedroom semi-detached property, with higher prices in London (Which? 2016). This arguably contributes to their overall ineffectiveness in preventing burglary (Tilley et al. 2015).
} 
This study used information from the environmental declarations to represent the carbon footprint of the installation of these products only and did not consider the embodied carbon of any products that may be replaced by newer or more secure products. In this way, we have assumed the choice between which measures to implement is at the beginning of a house design stage rather than crime prevention measures which have been retrofitted into existing homes. Incorporating carbon footprint estimates of security devices fitted in existing homes presents an additional extension of the current work.

The time period differences for SPF calculations (2008/2009-2011/2012), environmental declarations (2007-2015) and housing stock (2010) also demonstrate a further limitation (with a coincidental midpoint of 2010). The preventive effect and related SPF values of security devices and their combinations may well alter over time. This has been evident with burglar alarms, which used to prevent burglaries effectively in the period 1992-1996 (Tilley et al. 2015), unlike during the most recent years examined (2008/2009-2011/2012) in the current work. Replicating the current study for informing policy initiatives should rely on up-to-date SPF and carbon footprint estimates.

The current work gives conservative estimates for both the preventative effect and the carbon payback ratio of security measures. Our findings build on those of Tseloni et al.'s (2014), which assessed the effectiveness of these products but did not consider the carbon implications. The SPF's indicate the preventative effect of a security device(s) for a year due to crime survey constraints. As it would be realistic to assume that burglary risks for longer than annual time windows are higher than those within a year (Wittebrood and Nieuwbeerta 2000), the SPF values arguably underestimate the preventative effect of security during a 10-year period. In addition we only compared the footprint of burglary prevention measures to the footprint of a single burglary. It is likely that once installed these measures may prevent more than one incident of burglary taking place in the course of the 10 years of the devices' lifespan assumed here. Therefore, our study may also underestimate the level of carbon payback ratio, as the emissions associated with the consequences of two or more burglaries may be avoided.

Future research in this area could fine-tune both estimates of preventive effectiveness and carbon payback across different types of housing with due consideration also given to residing households' plausible accessibility to burglary security deriving from income and tenure constraints and their likely burglary incidence (mean number of burglaries rather than risks) over concurrent time periods. For example, it would be realistic to assume that the carbon payback ratio is even higher than estimated herein for particularly vulnerable households, such as social renters whose burglary risk and incidence are well above average (Hunter and Tseloni 2016; Tseloni and Thompson 2015).

\section{Decreasing the carbon footprint of burglary prevention}

A natural extension of this study is to consider how to reduce the footprint of the burglary prevention measures studied. There are many ways manufacturers can reduce the embodied carbon of their products. The process of commissioning an environmental 
declaration that estimates environmental impacts is a good starting point, since LCAs are considered a viable screening tool that can pinpoint environmental hotspots in complex value chains (Hellweg and Canals 2014). A common way to reduce emissions is to focus on the elements of the product with the highest impact first. For different products, savings can be made in various ways throughout the life cycle stages and, as noted by the European Commission's Integrated Product Policy Statement, it is important that all environmental impacts should be considered throughout the life cycle in an integrated way to ensure that negative impacts are not simply shifted from one part of the life cycle to another (European Commission 2003).

For manufacturing there are several ways to save embodied carbon of products, by using fewer materials, using alternative materials (higher recycled content), using 'clean' (renewable) electricity, or minimising waste (or re-using or recycling more) throughout the manufacturing process (WRAP 2016). For the construction of buildings (of which security measures may be considered a part), the use of recycled materials such as steel or aluminium, as a substitute for virgin materials, can confer savings up to $50 \%$ of the embodied energy (Chen et al. 2001). The way in which businesses monitor their environmental impact throughout manufacturing or distribution is also important, and the certification of environmental management systems has been shown to have a significantly positive effect on the innovation of more environmentally friendly products (Rehfeld et al. 2007). An example of how this approach has been applied within the security sector was recently demonstrated by a large door lock manufacturer: as a result of commissioning environmental product declarations (EPDs) for a range of it's products, for a particular door lock, the number of materials used was reduced (material weight and thickness without compromising strength), aspects were re-designed and a custom-made nickel and chrome-plated material was replaced with stainless steel (Assa Abloy 2016). As well as modifying existing products, this approach by this particular manufacturer is also to be taken forward for new product designs, which will be instrumental for ensuring sustainability is considered throughout their product range.

Obstacles to environmental product innovation mainly consist of the economic aspects (such as the higher price tag often associated with products which consider their impacts more wholly) (Rehfeld et al. 2007). Through the changes in the example above, however, the environmental impact was reduced along with a $15 \%$ reduction of manufacturing costs (Assa Abloy 2016), demonstrating the potential economic benefits that also exist. It is likely that because of the higher costs, this is the reason our search found that few companies have undertaken environmental declarations of burglary prevention measures and further research within this area is needed. Completion of more environmental declarations would improve the knowledge base of where improvements can be made in regards to environmental impacts of existing measures. Moreover, advancements in technology also have the potential to reduce the carbon emissions associated with crime prevention measures, and indeed newer and smarter products, with lower carbon footprints, may already be available.

Other types of burglary prevention that are not physical products may also potentially offer low-carbon solutions to preventing burglary and other types of 
crime. Examples of this include advice and guidance from websites such as police.uk and thecrimepreventionwebsite.com. Common sense measures, such as not leaving valuable items on show, is often important in reducing opportunities to commit crime, as highlighted by 'opportunity' being one of the key drivers of crime within the Home Office's Modern Crime Prevention Strategy (2016).

Other websites such as Immobilise.com-a national property register to help track items and repatriate them to the correct owner if they get stolen-also offer a presumed low-carbon service, as only the maintenance of the website and advertisements and travel associated with retrieving items would produce emissions. The reduction of emissions associated with the need to replace stolen items was highlighted as a large area of emissions (nearly 1.5 million tonnes $\mathrm{CO}_{2} \mathrm{e}$ ) arising due to crime (Skudder et al. 2016). Property registers such as this, therefore, may help save emissions by reducing the need for items to be replaced.

In addition, many (but not all) police forces in the UK have Crime Prevention Design Advisors (CPDAs), also known as Architectural Liaison Officers (ALOs) or Designing Out Crime Officers (DOCOs), who offer free advice on new building projects as part of planning applications. Again, this may contribute to a low-carbon burglary prevention strategy. One example is promotion of the planting of vegetation such as thorny bushes along property boundaries as a natural deterrent as advised by Secured by Design (2014). Security advice such as this may even indeed be carbon positive as plants take up $\mathrm{CO}_{2}$ from the atmosphere.

\section{Conclusion}

Our study is believed to be the first to help inform crime prevention specialists of the environmental impact of burglary prevention products and enable comparisons with the carbon emissions of the crimes they aim to prevent. We have shown that effective burglary prevention does not have a significant carbon footprint when compared to the emissions associated with burglaries that can be prevented. Window locks are found to be the most effective and low-carbon measure available individually. Combinations of window locks, door locks, external and indoor lighting (WIDE) are also shown to be effective and low-carbon. Burglar alarms and CCTV do not perform as strongly, with higher carbon footprints and lower security against burglary.

We have also shown that crime prevention measures may be able to offer more than monetary savings or reduced social impacts, as it is clear that careful choice of burglary prevention measures can save carbon emissions, whilst still ensuring a secure and safe home. It is encouraging that the security industry as a whole is beginning to pay attention to environmental impacts, as shown by the availability of environmental declarations related to burglary prevention measures. In future, there will be a greater need to consider environmental impacts and substantial emission reductions are required, in particular, over the next few decades to reduce climate risks (Pachauri et al. 2014)

Our findings are of considerable benefit to security professionals by highlighting that crime prevention measures have varying environmental costs, and that the most 
successful security measures are not necessarily the most carbon costly. In fact, the opposite is true, with many of the most successful security measures having a comparatively small carbon footprint, enabling security professionals to make winwin choices. This information could also be incorporated into future house building and renovation guidelines. There is already a need to consider the environmental impact of housing, but connecting this to crime prevention/security represents an additional benefit. For example, the opportunity to install security measures (better locks) could be combined with installation of energy saving or other environmentally friendly initiatives (double glazing).

The results presented in this paper also raise awareness of sustainability issues as part of security choices and offer an important contribution towards a growing connection between security and sustainability agendas. Cozens (2007), for example, highlighted an explicit need to integrate crime issues within sustainability frameworks. Also, Armitage and Gamman (2009) highlighted the importance of ensuring that any steps forward for the green agenda, such as minimising carbon emissions, do not present a step back for the crime agenda (and vice versa). We have shown that sustainability can be considered alongside security choices and that win-win measures (in terms of security and low-carbon) can be chosen to minimise impacts whilst not compromising safety.

As both security and sustainability considerations are often neglected in the face of economic pressures (with the exception of national security/national infrastructure concerns), awareness of these issues between sustainability and security professionals is essential to avoid long-lasting damage to the environment and risks to community safety.

We understand that security choices around the home are made in various ways, and it is unlikely that the carbon footprint of these products will be a deciding factor alone. But, if it is possible to secure homes against burglary while minimising the environmental impact, then low-carbon measures may be more favourable to householders concerned about the environment. We hope that by highlighting the footprints of common burglary prevention measures, this may help inform these choices further in the future and also advocate further research into these and other environmental impacts of crime prevention measures.

Acknowledgements This research forms part of an Engineering Doctoral project at the University of Surrey's Industrial Doctorate Centre and was supported by the Engineering and Physical Sciences Research Council (EPSRC) [Grant No. EP/G037612/1]; the Home Office (HM Government Department); and Secured by Design (Police Crime Prevention Initiatives Limited). Part of the analysis reported here was funded by the Economic and Social Research Council (ESRC), Secondary Data Analysis Initiative (SDAI) Phase 1 [Grant No. ES/K003771/1]. Many thanks are extended to those who provided helpful and insightful comments on previous drafts of this paper.

Open Access This work is licensed under a Creative Commons Attribution 3.0 Unported License. The images or other third party material in this article are included in the article's Creative Commons license, unless indicated otherwise in the credit line; if the material is not included under the Creative Commons license, users will need to obtain permission from the license holder to reproduce the material. To view a copy of this license, visit http://creativecommons.org/licenses/by/3.0/. 


\section{Appendix 1: Search strategy}

There are many different environmental declaration schemes, and this is the first study to attempt to collate environmental declarations for security products. Therefore, a systematic literature review approach was taken to find environmental declarations of our selected crime-related measures (door locks, window locks, burglar alarms, lighting — indoor and external with a timer or sensor-and CCTV systems). The search period was November 2015 to March 2016.

The search strategy initially utilised keywords in a popular online search website (Google) to locate the environmental declarations. The searches contained keywords relating to the crime prevention aspects (i.e. 'security', 'burglary') and the products themselves (i.e. 'lighting', 'cctv', 'alarm', 'lock', 'window', 'door', 'camera'). These broad terms were limited by exclusively searching for these in combination with references to the environmental declarations or LCA type results (i.e. using the terms 'ISO 14025', 'environmental product declaration', 'product environmental profile', 'GWP' or ' $\mathrm{CO}_{2}$ '). When an environmental declaration was found, the company website was also searched in order to identify other declarations for similar products that may also be relevant, as companies which have undertaken environmental declaration studies often undertake this for a range of products rather than just a single product.

The initial search also led to websites of databases for various environmental declaration programs such as the International EPD System (EPD International 2016), ASTM EPD program (ASTM International 2016), IBU EPD program (Institut Bauen und Umwelt e.V 2016), EcoLeaf Environmental Labels (JEMAI 2016) and the PEP Eco Passport program (Association P.E.P 2016) among others. Systematic searches through these databases were also performed to ensure that relevant products were found wherever possible.

\section{Appendix 2: Typical household assumptions}

As the number of doors and windows in homes varies considerably based on the type of home, we use weighted averages to represent the household footprint. Table 5 details assumptions used concerning the number of windows and doors per household. These are based on a previous study assessing the capital cost of Secured by Design measures (Davis Langdon 2010) combined with estimates of the proportion of each house type from the English Housing Survey (DCLG 2016).

Once the number of doors in a house was estimated, we established the number of door locks per household using the Metropolitan Police Service (Met police) guidance for door security. We assumed that front doors have two locks, whereas rear access or other doors only have one (Met Police 2016). Therefore, each household is assumed to have four locks (one front door with two locks and two other doors with one lock each).

We established the number of window locks per window using a weighted average of the number of locks needed for different window types (PVC and timber) available to buy from popular DIY merchants in the UK, as detailed in Table 6. The 
Table 5 Estimation of the average number of windows and doors per household in the UK

\begin{tabular}{|c|c|c|c|c|}
\hline House types & $\begin{array}{l}\text { Number of } \\
\text { households } \\
\text { (DCLG 2016) }\end{array}$ & $\begin{array}{l}\text { Proportion } \\
\text { of total }\end{array}$ & $\begin{array}{l}\text { Number of windows per } \\
\text { house type } \\
\text { (Davis Langdon 2010) }\end{array}$ & $\begin{array}{l}\text { Number of doors per } \\
\text { house type } \\
\text { (Davis Langdon 2010) }\end{array}$ \\
\hline Detached & $6,191,079$ & $26 \%$ & 11 & 4 \\
\hline Semi-detached & $5,790,666$ & $25 \%$ & 8 & 4 \\
\hline Terraced & $6,729,747$ & $29 \%$ & 6 & 3 \\
\hline \multirow[t]{2}{*}{ Flats/maisonettes } & $4,659,459$ & $20 \%$ & 5 & 1.25 \\
\hline & $\begin{array}{l}\text { Total } \\
23,370,951\end{array}$ & Total $100 \%$ & $\begin{array}{l}\text { Weighted average per } \\
\text { household } 8\end{array}$ & $\begin{array}{l}\text { Weighted average per } \\
\text { household } 3\end{array}$ \\
\hline
\end{tabular}

Table 6 Estimation of the number of locks found on windows available to buy on popular DIY websites in the UK

\begin{tabular}{|c|c|c|c|}
\hline Number of locks & Number of windows & Proportion of total $(\%)$ & $\begin{array}{l}\text { Weighted average } \\
\text { number of locks }\end{array}$ \\
\hline \multicolumn{4}{|c|}{ Wickes PVC windows (Wickes 2016a) } \\
\hline 1 & 16 & 64 & 0.64 \\
\hline 2 & 7 & 28 & 0.56 \\
\hline 3 & 2 & 8 & 0.24 \\
\hline Total & 25 & 100 & 1.44 \\
\hline \multicolumn{4}{|c|}{ Wickes timber windows (Wickes 2016b) } \\
\hline 1 & 10 & 56 & 0.56 \\
\hline 2 & 6 & 33 & 0.67 \\
\hline 3 & 2 & 11 & 0.33 \\
\hline Total & 18 & 100 & 1.56 \\
\hline \multicolumn{4}{|c|}{ B and Q PVC windows (B \& Q 2016b) } \\
\hline 1 & 8 & 89 & 0.89 \\
\hline 2 & 1 & 11 & 0.22 \\
\hline Total & 9 & 100 & 1.11 \\
\hline \multicolumn{4}{|c|}{$\mathrm{B}$ and $\mathrm{Q}$ timber windows (B \& Q 2016c) } \\
\hline 1 & 10 & 56 & 0.56 \\
\hline 2 & 6 & 33 & 0.67 \\
\hline 3 & 2 & 11 & 0.33 \\
\hline Total & 18 & 100 & 1.56 \\
\hline \multicolumn{3}{|c|}{ Overall weighted average } & 1.42 \\
\hline
\end{tabular}

number of locks per window was therefore assumed to be 1.4. With an average of eight windows per household (Table 5), this meant that 11.4 locks were assumed to be present in each household.

We assumed that external lighting or CCTV cameras $^{9}$ were installed by both the front and back doors in a household (i.e. each of these measures therefore required

\footnotetext{
${ }^{9}$ We acknowledge that realistically these two devices do not form alternatives for every household: only those on very high income would consider fitting CCTV systems, whereas external lighting is accessible to most households.
} 
three per household). To create the illusion of someone occupying a house to deter burglars, only one indoor light on a sensor or timer was assumed to be needed. For burglar alarm systems, we assumed that one control unit, one ringer and two sensors were present within each household. ${ }^{10}$

The lifespan (or service life) of the products is indicated in environmental declarations where they consider the in-use stage of the life cycle. The lifespan of burglar alarms, indoor lights and external lighting products, indicated in the environmental declarations, was ten years, whereas a CCTV camera was only five years. This means that the footprint of CCTV was doubled as we assume that two will be needed to cover the 10 -year period of the household footprint. For window and door locks, the in-use phase of the life cycle is not included as no energy consumption is required during use of these mechanical products and so, they are assumed to last the 10-year period also (although it is likely that they will last longer than this period).

\section{Appendix 3: Data}

See Tables 7 and 8.

Table 7 Environmental Declarations included within study

\begin{tabular}{lllll}
\hline $\begin{array}{l}\text { Crime } \\
\text { prevention } \\
\text { measure }\end{array}$ & Product name & Declaration number & Organisation & Year \\
\hline Door locks & & & \\
& $\begin{array}{l}\text { Mortise/tubular frame door } \\
\text { lock }\end{array}$ & EPD-FVS-2011111-E & FVSB & 2011 \\
& Multi-point lock & EPD-FVS-2011111-E & FVSB & 2011 \\
& $\begin{array}{l}\text { Electromechanical multi- } \\
\text { point lock }\end{array}$ & EPD-FVS-2011111-E & FVSB & 2011 \\
& Single-point lock & EPD-ASA-20150137-IBA1-EN & Assa abloy & 2015 \\
& Mortise lock & EPD-ASA-20150138-IBA1-EN & Assa abloy & 2015 \\
& Triton Scandinavian Oval & EPD-ASA-20150098-IBA1-EN & Assa & 2015 \\
& Triton Scandinavian Round & EPD-ASA-20150101-IBA1-EN & Assa & 2015 \\
& $\begin{array}{l}\text { Profile cylinder } \\
\text { Industrial cylinder }\end{array}$ & EPD-FVS-2011411-E & FVSB & 2011 \\
& Electronic profile cylinder & EPD-FVS-2011411-E & FVSB & 2011 \\
& Electronic mortise & EPD-FVS-2011411-E & FVSB & 2011 \\
& cylinder-Medeco CLIC & & Assa abloy & 2015 \\
\hline
\end{tabular}

${ }^{10}$ Represents the typical burglar alarm system box contents on popular security and DIY websites (B \& Q 2016a; Yale 2016), with the exclusion of door contacts, key fobs or panic buttons as no environmental declarations of these components could be found. 
Table 7 continued

\begin{tabular}{|c|c|c|c|c|}
\hline $\begin{array}{l}\text { Crime } \\
\text { prevention } \\
\text { measure }\end{array}$ & Product name & Declaration number & Organisation & Year \\
\hline \multirow[t]{3}{*}{ Window locks } & $\begin{array}{l}\text { Window fittings (for wooden } \\
\text { windows) }\end{array}$ & EPD-FVS-2011311-E & $\begin{array}{l}\text { Roto Frank } \\
\quad \text { AG }\end{array}$ & 2011 \\
\hline & $\begin{array}{l}\text { Window fittings (for plastic } \\
\text { windows) }\end{array}$ & EPD-FVS-2011311-E & $\begin{array}{l}\text { Roto Frank } \\
\text { AG }\end{array}$ & 2011 \\
\hline & $\begin{array}{l}\text { Window sliding hardware with } \\
\text { locks }\end{array}$ & EPD-FVS-20130198-IBG1-EN & FVSB & 2013 \\
\hline \multirow[t]{6}{*}{ Indoor lights } & BANG CFL-G24Q & SLFB-0005-V1 & Securlite & 2012 \\
\hline & BANG CFLI-E27 & SLFB-0004-V1 & Securlite & 2012 \\
\hline & $\begin{array}{l}\text { VOILA SENSOR CFL LAMPS- } \\
\text { G24Q }\end{array}$ & SLFB-0027-V1 & Securlite & 2012 \\
\hline & VOILA SENSOR 12 LEDS & SLFB-0029-V1 & Securlite & 2012 \\
\hline & BANG ROUND SENSOR 9 LEDS & SLFB-0001-V1 & Securlite & 2012 \\
\hline & $\begin{array}{l}\text { BANG ROUND SENSOR } 12 \\
\text { LEDS }\end{array}$ & SLFB-0007-V1 & Securlite & 2012 \\
\hline \multirow[t]{4}{*}{ External lights } & $\begin{array}{l}\text { RONDO PERFORMANCE } \\
\text { METALLIC IODIDE LAMP }\end{array}$ & SLFB-0017-V1 & Securlite & 2012 \\
\hline & $\begin{array}{l}\text { RONDO SENSOR CFL LAMPS } \\
\text { GX24Q PROFESSIONAL }\end{array}$ & SLFB-0018-V1 & Securlite & 2012 \\
\hline & RONDO SENSOR LED & SLFB-0020-V1 & Securlite & 2012 \\
\hline & RONDO LED & SLFB-0019-V1 & Securlite & 2012 \\
\hline \multirow{2}{*}{$\begin{array}{l}\text { Burglar alarm } \\
\quad \text { (control unit) }\end{array}$} & Central LS radio alarm & HAGE-2013-022-V1-EN & Hager & 2013 \\
\hline & Central & HAGE-2012-013-V1-EN & Hager & 2012 \\
\hline \multirow{2}{*}{$\begin{array}{l}\text { Burglar alarm } \\
\quad \text { (ringer) }\end{array}$} & Alarm CS8000 TYXAL+ & DDOR-2015-006-V1-EN & Delta DORE & 2015 \\
\hline & Central siren Proxeo & HAGE-2014-015-V1-EN & Hager & 2014 \\
\hline \multirow{10}{*}{$\begin{array}{l}\text { Burglar alarm } \\
\quad \text { (sensor) }\end{array}$} & Alarm sensor & LGRP-2011-518-v1-en & Legrand & 2011 \\
\hline & $\begin{array}{l}\text { Motion detectors } 360 \text { ceiling } \\
\text { mounted }\end{array}$ & HAGE-2012-004-V1-EN & Hager & 2012 \\
\hline & DMB TYXAL + (6412286) & DDOR-2015-001-V1-EN & Delta DORE & 2015 \\
\hline & DO TYXAL BL + (6412288) & DDOR-2015-002-V1-EN & Delta DORE & 2015 \\
\hline & MDO TYXAL BL + (6412305) & DDOR-2015-004-V1-EN & Delta DORE & 2015 \\
\hline & DMBD TYXAL + (6412311) & DDOR-2015-014-V1-EN & Delta DORE & 2015 \\
\hline & ССТ56Р004 & ENVPEP1311030EN & $\begin{array}{l}\text { Schneider } \\
\text { Electronic }\end{array}$ & 2011 \\
\hline & $\begin{array}{l}\text { CCT56P002 } 360 \text { Ceiling Indoor or } \\
\text { Outdoor PIR }\end{array}$ & SCHN-2011-450-V0 & $\begin{array}{l}\text { Schneider } \\
\text { Electronic }\end{array}$ & 2011 \\
\hline & Round HBNet motion detector & HAGE-2013-005-V1-EN & Berker & 2013 \\
\hline & Motion detector kallysto.pur & HAGE-2013-003-V1-EN & Hager & 2013 \\
\hline \multirow[t]{7}{*}{ CCTV } & BL-C111 & BH-07-027 & Panasonic & 2007 \\
\hline & BL-C131 & BH-07-028 & Panasonic & 2007 \\
\hline & BL-C161KT & BH-08-040 & Panasonic & 2008 \\
\hline & VL-CM210 & ВH-09-047 & Panasonic & 2009 \\
\hline & VL-CM240 & BH-09-048 & Panasonic & 2009 \\
\hline & VL-CM260 & ВH-09-049 & Panasonic & 2009 \\
\hline & DMBV TYXAL + (6412287) & DDOR-2015-016-V1-FR & Delta DORE & 2015 \\
\hline
\end{tabular}


Table 8 Full results of security measure(s), security protection factor (SPF), carbon footprint $\left(\mathrm{kg} \mathrm{CO}_{2} \mathrm{e}\right)$ and carbon payback ratio (burglary footprint over security measure footprint)

\begin{tabular}{|c|c|c|c|c|c|c|c|}
\hline \multirow[t]{2}{*}{$\begin{array}{l}\text { Security } \\
\text { measure(s) }\end{array}$} & \multirow{2}{*}{$\begin{array}{l}\text { Security protection } \\
\text { factor (SPF) } \\
\text { from Tseloni } \\
\text { et al. (2014) }\end{array}$} & \multicolumn{3}{|c|}{$\begin{array}{l}\text { Carbon footprint } \\
\left(\mathrm{kg} \mathrm{CO}_{2} \mathrm{e}\right)\end{array}$} & \multicolumn{3}{|c|}{$\begin{array}{l}\text { Carbon payback ratio } \\
\text { (burglary footprint over } \\
\text { measure(s) footprint) }\end{array}$} \\
\hline & & Min & Median & $\operatorname{Max}$ & Best & Median & Worst \\
\hline B & 0.89 & 338.5 & 389.9 & 580.5 & 3.0 & 2.5 & 1.7 \\
\hline $\mathrm{C}$ & 1.59 & 26.3 & 397.9 & 519.5 & 38.1 & 2.5 & 1.9 \\
\hline D & 2.79 & 1.5 & 12.5 & 50.8 & 672.8 & 79.7 & 19.6 \\
\hline $\mathrm{E}$ & 3.01 & 285.9 & 403.5 & 423.0 & 3.5 & 2.5 & 2.4 \\
\hline I & 3.50 & 39.9 & 60.4 & 102.0 & 25.1 & 16.6 & 9.8 \\
\hline W & 6.58 & 44.5 & 47.5 & 50.2 & 22.5 & 21.0 & 19.9 \\
\hline BD & 1.96 & 340.0 & 402.4 & 631.4 & 2.9 & 2.5 & 1.6 \\
\hline $\mathrm{CW}$ & 14.54 & 70.8 & 445.4 & 569.7 & 14.1 & 2.3 & 1.8 \\
\hline WD & 12.54 & 46.0 & 60.1 & 101.0 & 21.8 & 16.7 & 9.9 \\
\hline ED & 10.77 & 287.3 & 416.0 & 473.8 & 3.5 & 2.4 & 2.1 \\
\hline EW & 17.76 & 330.4 & 451.0 & 473.2 & 3.0 & 2.2 & 2.1 \\
\hline ID & 9.62 & 41.4 & 72.9 & 152.8 & 24.2 & 13.7 & 6.5 \\
\hline IW & 8.33 & 84.4 & 107.89 & 152.2 & 11.9 & 9.3 & 6.6 \\
\hline WB & 4.68 & 383.0 & 437.4 & 630.7 & 2.6 & 2.3 & 1.6 \\
\hline CWD & 24.01 & 72.2 & 458.0 & 620.5 & 13.8 & 2.2 & 1.6 \\
\hline EBD & 6.71 & 625.9 & 805.9 & 1054.4 & 1.6 & 1.2 & 1.0 \\
\hline EID & 9.17 & 327.3 & 476.4 & 575.8 & 3.1 & 2.1 & 1.7 \\
\hline EIW & 13.20 & 370.3 & 511.4 & 575.2 & 2.7 & 2.0 & 1.7 \\
\hline EWB & 10.25 & 668.9 & 840.9 & 1053.7 & 1.5 & 1.2 & 1.0 \\
\hline EWD & 34.41 & 331.9 & 463.6 & 524.0 & 3.0 & 2.2 & 1.9 \\
\hline IWB & 6.26 & 422.9 & 497.8 & 732.7 & 2.4 & 2.0 & 1.4 \\
\hline IWD & 16.54 & 85.9 & 120.4 & 203.0 & 11.7 & 8.3 & 4.9 \\
\hline WBD & 8.92 & 384.5 & 450.0 & 681.6 & 2.6 & 2.2 & 1.5 \\
\hline EIWB & 11.52 & 708.8 & 901.3 & 1155.7 & 1.4 & 1.1 & 0.9 \\
\hline WIDE & 49.12 & 371.8 & 523.9 & 626.0 & 2.7 & 1.9 & 1.6 \\
\hline EWBD & 16.49 & 670.4 & 853.5 & 1104.6 & 1.5 & 1.2 & 0.9 \\
\hline IWBD & 18.24 & 424.4 & 510.3 & 783.6 & 2.4 & 2.0 & 1.3 \\
\hline CEWBD & 32.44 & 696.7 & 1251.3 & 1624.1 & 1.4 & 0.8 & 0.6 \\
\hline EIWBD & 29.62 & 710.3 & 913.8 & 1206.6 & 1.4 & 1.1 & 0.8 \\
\hline CEIWBD & 34.00 & 736.6 & 1311.7 & 1726.1 & 1.4 & 0.8 & 0.6 \\
\hline
\end{tabular}

$W$ window locks, $D$ door double or deadlocks, $E$ external lights on a timer or sensor switch, $I$ indoor lights on a timer or sensor switch, $B$ burglar alarm, $C$ CCTV

\section{References}

Abloy, Assa. 2015. Environmental product declaration: Electronic cylinders-Medeco3 CLIQ mortise cylinder. Virginia: Assa Abloy. 
Aebi, M.F., and A. Linde. 2010. Is there a crime drop in Western Europe? European Journal on Criminal Policy and Research 16(4): 251-277.

Angel, S. 1968. Discouraging crime through city planning. Berkeley: University of California Institute of Urban \& Regional Development.

Armitage, R., and L. Gamman. 2009. Sustainability via Security: a new look. Built Environment 35(3): 294

Armitage, R., and L. Monchuk. 2009a. Re-evaluating Secured by Design (SBD) Housing in West Yorkshire, ACPO Secured by Design in partnership with University of Huddersfield and West Yorkshire Police. http://www.securedbydesign.com/pdfs/Re-evaluating-SBD-Housing-in-WestYorks.pdf. Accessed Jan 2015.

Armitage, R., and L. Monchuk. 2009b. Reconciling security with sustainability: The challenge for ecohomes. Built Environment 35(3): 308-327.

Armitage, R., L. Monchuk, and K. Pease. 2008. Sustainability via security: Aligning the agendas. London: ACPO Secured by Design.

Assa Abloy, 2016. Certification demand leads to sustainable product. http://www.assaabloy.com/en/com/ sustainability/news1/assa-abloy-sicherheitstechnik-gmbh-albstadt-germany/. Accessed Aug 2016.

Association P.E.P. 2016. PEP ecopassport program, http://www.pep-ecopassport.org/. Accessed Oct 2016.

ASTM International. 2016. Environmental product declarations. http://www.astm.org/CERTIFICATION/ EpdAndPCRs.html. Accessed Oct 2016.

B \& Q. 2016a. Response wirefree home alarm system. http://www.diy.com/departments/responsewirefree-home-alarm-system/30053_BQ.prd. Accessed June 2016.

B \& Q. 2016b. PVC windows. http://www.diy.com/departments/doors-windows/windows/pvc-windows/ DIY1441561.cat. Accessed May 2016.

B \& Q. 2016c. Timber windows. http://www.diy.com/departments/doors-windows/windows/timberwindows/DIY570043.cat. Accessed May 2016.

BRE. 2016. BREEAM standards: Hea 06 safety and security. http://www.breeam.com/ BREEAMUK2014SchemeDocument/content/05_health/hea06.htm. Accessed Jan 2017.

BSI. 2010. BS EN ISO 14025: 2010: Environmental labels and declarations-Type III environmental declarations-Principles and procedures. London: British Standards Institution.

Chen, T.Y., J. Burnett, and C.K. Chau. 2001. Analysis of embodied energy use in the residential building of Hong Kong. Energy 26(4): 323-340. doi:10.1016/S0360-5442(01)00006-8.

Clarke, R.V.G., and P. Mayhew. 1980. Designing out crime. London: HM Stationery Office.

Clarke, R.V.G., and G.R. Newman. 2006. Outsmarting the terrorists. Portsmouth: Greenwood Publishing Group.

Clarke, R.V., and D. Weisburd. 1994. Diffusion of crime control benefits: Observations on the reverse of displacement. Crime prevention studies 2: 165-184.

Climate Change Act. 2008. Elizabeth II. Chapter 27. http://www.legislation.gov.uk/ukpga/2008/27/ contents. Accessed Feb 2017.

Cozens, P. 2007. Planning, crime and urban sustainability. WIT transactions on ecology and the environment 102: 10 .

Davis Langdon. 2010. Capital costs of Secured by Design Accreditation. http://www.securedbydesign. com/wp-content/uploads/2014/02/the-capital-costs-of-secured-by-designdavis-langdon.pdf. Accessed May 2016.

DCLG. 2016. English Housing Survey 2014-2015: headline report. https://www.gov.uk/government/ statistics/english-housing-survey-2014-to-2015-headline-report. Accessed Apr 2016.

EPD International. 2016. The international EPD system. http://www.environdec.com/. Accessed Oct 2016.

European Commission. 2003. Communication from the Commission to the Council and the European Parliament: Integrated product policy: building on environmental life-cycle thinking. Brussels: Commission of the European Communities.

Farrell, G., N. Tilley, and A. Tseloni. 2014. Why the crime drop? Crime and Justice 43(1): 421-490.

Farrell, G., A. Tseloni, and N. Tilley. 2011. The effectiveness of vehicle security devices and their role in the crime drop. Criminology and Criminal Justice 11(1): 21-35.

Gardiner, R.A. (1978) Design for safe neighborhoods: The environmental security planning and design process. Washington, DC: Department of Justice, Law Enforcement Assistance Administration, National Institute of Law Enforcement and Criminal Justice. 
Ghumra, S. 2016. In All very revealing, ed. G. Miller. The Environmentalist. http://www. environmentalistonline.com/article/all-very-revealing. Accessed July 2016.

Hellweg, S., and L.M. i Canals. 2014. Emerging approaches, challenges and opportunities in life cycle assessment. Science 344(6188): 1109-1113. doi:10.1126/science.1248361.

HM Government. 2015. The building regulations 2010: Security-Dwellings approved document Q. http://www.planningportal.gov.uk/uploads/br/BR_PDF_AD_Q_2015.pdf. Accessed Jan 2016.

HMIC. 2014. State of policing: The annual assessment of policing in England and Wales 2012/13. http:// www.hmic.gov.uk/wp-content/uploads/2014/03/state-of-policing-12-13.pdf. Accessed Nov 2015.

Home Office. 2004. Safer places: The planning system and crime prevention. https://www.gov.uk/ government/publications/safer-places-the-planning-system-and-crime-prevention. Accessed Mar 2016.

Home Office. 2016. Modern crime prevention strategy. https:/www.gov.uk/government/publications/ modern-crime-prevention-strategy. Accessed May 2016.

Home Office, and Ministry of Justice. 2011. Integrated offender management: Efficiency toolkit: Phase two: Conducting break-even analysis of integrated offender management. https://www.gov.uk/ government/uploads/system/uploads/attachment_data/file/118039/IOM-Toolkit-Phase-2.pdf. Accessed 10 Sept 2011.

Hunter, J., and A. Tseloni. 2016. Equity, justice and the crime drop: The case of burglary in England and Wales. Crime Science 5(1): 1 .

Institut Bauen und Umwelt e.V. 2016. EPD program. http://ibu-epd.com/en/epd-program/. Accessed Oct 2016.

Jacobs, J. 2010. The death and life of great American cities. West Sussex: Wiley.

Jeffery, C.R. 1971. Crime prevention through environmental design. Beverly Hills: Sage.

JEMAI. 2016. Japan Environmental Management Association for Industry: Ecoleaf environmental label. http://www.ecoleaf-jemai.jp/eng/. Accessed Oct 2016.

Lynch, K. 1960. The image of the city. Cambridge: MIT press.

Met Police. 2016. Home security: Doors. http://www.met.police.uk/crimeprevention/mobile/doors.htm. Accessed June 2016.

Mori Social Research Institute. 2002. CABE Mori Poll 2002. London: Commission for Architecture the Built Environment.

Newman, O. 1973. Defensible space people and design in the violent city. London: Architectural Press.

ONS. 2013. Chapter 3-Burglary and Home Security. http://webarchive.nationalarchives.gov.uk/ 20160105160709/http://www.ons.gov.uk/ons/dcp171776_340685.pdf. Accessed Nov 2016.

Pachauri, R.K., M.R. Allen, V.R. Barros, J. Broome, W. Cramer, R. Christ, J.A. Church, L. Clarke, Q. Dahe, and Dasgupta, P. 2014. Climate change 2014: synthesis report. Contribution of working groups I, II and III to the fifth assessment report of the intergovernmental panel on climate change, IPCC.

Pease, K. 2009. The carbon cost of crime and its implications. London: ACPO Secured by Design.

police.uk. 2016. Crime prevention advice: burglary. https:/www.police.uk/crime-prevention-advice/ burglary/. Accessed Aug 2016.

Poyner, B. 1983. Design against crime: Beyond defensible space. London: Butterworths.

Rehfeld, K., K. Rennings, and A. Ziegler. 2007. Integrated product policy and environmental product innovations: An empirical analysis. Ecological Economics 61(1): 91-100.

RICS. 2012. Methodology to calculate embodied carbon of materials, RICS, information Paper, RICS QS \& construction Standards, IP32/2012. http://www.rics.org/Documents/Methodology_embodied_ carbon_final.pdf. Accessed Mar 2016.

Secured by Design. 2015. Home Security Tips and Advice. http://www.securedbydesign.com/aware/ security-hints-and-tips.pdf. Accessed July 2015.

Skudder, H., A. Druckman, J. Cole, A. McInnes, I. Brunton-Smith, and G. Ansaloni. 2016. Addressing the carbon-crime blind spot: A carbon footprint approach. Journal of Industrial Ecology, In Press.. doi:10.1111/jiec. 12457.

Tilley, N., R. Thompson, G. Farrell, L. Grove, and A. Tseloni. 2015. Do burglar alarms increase burglary risk? A counter-intuitive finding and possible explanations. Crime Prevention \& Community Safety 17(1): 1-19.

Tseloni, A., and R. Thompson. 2015. Securing the premises. Significance 12(1): 32-35.

Tseloni, A., R. Thompson, L. Grove, N. Tilley, and G. Farrell. 2014. The effectiveness of burglary security devices. Security Journal. doi:10.1057/sj.2014.30. 
UNFCC. 2015. Adoption of the Paris Agreement. United Nations framework convention on climate change. https://unfccc.int/resource/docs/2015/cop21/eng/109r01.pdf. Accessed Aug 2016.

United Nations. 2016. The global goals for sustainable development. http://www.globalgoals.org/. Accessed July 2016.

Van Dijk, J. 2007. The world of crime: Breaking the silence on problems of security, justice and development across the world. Thousand Oaks: Sage.

Vollaard, B., and J.C. Van Ours. 2011. Does regulation of built-in security reduce crime? Evidence from a natural experiment. The Economic Journal 121(552): 485-504.

Welsh, B.C., and D.P. Farrington. 1999. Value for money? A review of the costs and benefits of situational crime prevention. British Journal of Criminology 39(3): 345-368.

Which?. 2016. Burglar Alarms. http://www.which.co.uk/reviews/burglar-alarms-and-home-security/ article/burglar-alarms-and-home-security/burglar-alarms?category=burglar-alarms-and-home-security . Accessed Oct 2016.

Wickes. 2016a. PVC windows. http://www.wickes.co.uk/Products/Doors+Windows/Windows/uPVCWindows+Accessories/uPVC. Accessed Apr 2016.

Wickes. 2016b. Timber windows. http://www.wickes.co.uk/Products/Doors+Windows/Windows/ Timber-Windows/c/1000633. Accessed Apr 2016.

Wittebrood, K., and P. Nieuwbeerta. 2000. Criminal victimization during one's life course: The effects of previous victimization and patterns of routine activities. Journal of Research in Crime and Delinquency 37(1): 91-122.

WRAP. 2016. Cutting embodied carbon in construction projects. http://www.wrap.org.uk/sites/files/wrap/ FINAL\%20PRO095-009\%20Embodied\%20Carbon\%20Annex.pdf. Accessed Aug 2016.

Yale. 2016. Telecommunicating alarm kit. http://www.yale.co.uk/en/yale/couk/productsdb/alarms/-efseries-alarms-accessories/Telecommunicating-Alarm-Kit—EF-KIT2/. Accessed July 2016. 